\title{
Association of isozyme marker-genes on chromosome 6 with resistance to MDMV in maize
}

\author{
D Ignjatović *, D Ivanović, B Tadić \\ Maize Research Institute, Zemun Polje, Belgrade-Zemun, Serbia
}

(Received 20 May 1995; accepted 4 July 1995)

\begin{abstract}
Summary - In order to determine the precise position of Mdm1 on the maize chromosome map, isozymes of the chromosome 6 were used as genetic markers. Parental homozygous lines were chosen by both divergence in MDMV resistance and presence of segregating isozyme markers. Two resistant (R: 38-11, B84) and 2 susceptible (S: Mo17, Oh43) lines and BC (F1 x S parent) progenies of 4 crosses (R x S) were analysed. Resistance scoring of mechanically inoculated plants was performed visually. The obtained ratio of $R$ vs $S$ plants showed that the degree of resistance depended on the susceptible parent genotype. Recombination percentage between Mdm 1 and chromosome 6 isozyme loci showed apparent association only with the Pgd1 (6-phosphogluconate dehydrogenase) locus. The distance between these 2 loci is $14-22$ recombination units.
\end{abstract}

isozyme marker / maize / MDMV / Mdm1 / resistance

Résumé - Association entre isozymes marqueurs sur le chromosome 6 et la résistance au virus de la mosaïque nanisante du maïs chez le maïs. Pour déterminer la position exacte de Mdm1 sur la carte chromosomique du maïs, les isozymes du chromosome 6 ont été utilisés comme marqueurs. Des lignées parentales ont été choisies à la fois pour leur différence de résistance au MDMV, et pour la présence de marqueurs en ségrégation. Deux lignées résistantes, (R:38-11, B84) et 2 sensibles (S:Mo17, Oh43) et leurs descendances en back-cross (F1 x parent S) ont été analysées. L'évaluation de la résistance des plantes inoculées a été faite visuellement. Le rapport obtenu $R / S$ a montré que le degré de résistance dépend du génotype parental sensible. Le pourcentage de recombinaison entre Mdm1 et le locus de l'isozyme sur le chromosome 6 montre une association nette entre le locus de Mdm1 et celui de Pgd1 (6-phosphogluconate déshydrogénase). La distance entre les 2 loci est de 14 à 22 unités de recombinaison.

isozymes marqueurs / maïs / virus de la mosaïque nanisante du maïs (MDMV) / résistance

\section{INTRODUCTION}

Maize dwarf mosaic virus (MDMV) causes one of the most significant viral diseases of this plant in the moderate climate regions. Genetic research into MDMV resistance started in the early 1970s. For a long time it was considered a polygenic trait. The number of estimated genes controlling MDMV resistance varied from 2 to 10 (Findley et al, 1973; Rosenkranz and Scott, 1984), depending on the genotypes used, environmental conditions, the mode of infection and methods used for the disease estimation (Ivanovic et al, 1992). When plants were mechanically inoculated, with-

\footnotetext{
* Correspondence and reprints
} 
out the natural source of infection, the ratios of $R$ vs $S$ plants obtained were consistent with the 1gene hypothesis (Roane et al, 1983; Ivanović et al, 1992).

Both arms of chromosome 6 are involved in MDMV resistance (Findley et al, 1973). The distance between Mdm1 and $\mathrm{y} 1$ (endosperm color) is between 10 and 35 recombination units (Scott, 1989). In the work of Louie et al (1991) it was shown that Mdm1 was located near the UMC85 and BNL 6.29 RFLP markers. The presence of $\mathrm{Mdm} 1$ is necessary for any resistance answer to MDMV infection, but the degree of resistance is dependent on the susceptible parent genotype. This might be an explanation for the large differences in the estimated number of resistance genes, even for the same genotype.

\section{MATERIALS AND METHODS}

The choice of parental homozygous lines was made using 2 criteria: divergence in MDMV resistance and presence of segregating isozyme markers of chromosome 6. Two resistant (R: 38-11, B84) and 2 susceptible (S: Mo17, Oh43) inbred lines and $B C\left(F_{1} \times S\right.$ parent) progenies of 4 crosses $R \times S,(38-11 \times$ Mo17) $\times$ Mo17, (38-11 x Oh43) x Oh43, (B84 x Mo17) $\times$ Mo17 and $(B 84 \times$ Oh43) $\times$ Oh43, were scored for MDMV resistance and analysed for isozymes.

Coleoptile samples of $\mathrm{BC}$ generation seedlings were taken $5 \mathrm{~d}$ after germination on $25^{\circ} \mathrm{C}$. They were then planted in pots and kept under controlled conditions till the 3-leaf stage, when they were transplanted in the field. The first inoculation was performed at the 2-leaf stage and the second $10 \mathrm{~d}$ after the transplantation.

$\mathrm{BC}$ plants were scored visually, using the scale from 1 (healthy) to 6 (systemic infection). The symptom appearance on BC plants was observed and noted during the 6 week period after the first inoculation. Depending on visual scoring and incubation period plants were classified in R (rates 1,2 and 3 ) or $S$ (rates 4, 5 and 6) groups. Data for BC generation were analysed by the $\chi^{2}$ test.

Parental inbred lines and BC progeny were screened for isozymes of chromosome 6 by the method of horizontal electrophoresis on starch gel, followed by corresponding histochemical dying (Stuber et al, 1988). Endopeptidase 1 (Enp1) was analysed on C, hexokinase 2 ( $\mathrm{Hex} 2$ ) on $F$, while malate dehydrogenase 2 (Mdh2) and isocitrate dehydrogenase (Idh2) were analysed on $D$ buffer systems.

Each plant out of 200 plants per cross was determined as R or S to MDMV and screened for segregating isozymes. Association between $\mathrm{Mdm} 1$ and isozyme marker genes was calculated as percentage of recombinant genotypes. $R$ plants without the allozyme characteristic for $R$ parent and $S$ plants with the allozyme derived from $R$ parent were considered as recombinant genotypes.

\section{RESULTS}

Resistance scoring of $\mathrm{BC}$ progeny and $\chi^{2}$ values are presented in table I. The expected ratio of $R$ $v s \mathrm{~S}$ plants for 1-gene resistance was 1:1. Values obtained were $1: 1.02$ and 1.17:1 (for 38-11 $x$ Mol17) $x$ Mol 17 and (38-11 $\times$ Oh43) $\times$ Oh43, respectively. In crosses with Oh43 as a susceptible parent this ratio was $1: 1.6$ and 1:2.35 with 38 11 and B84, respectively.

The incubation periods of $B C$ generation plants of all 4 crosses are shown in figure 1 . Percentages of new plants with symptoms per week are similar in crosses to Mo17 and in crosses to Oh43.

The isozyme screening of parental lines revealed segregating markers in $\mathrm{R} \times \mathrm{S}$ crosses. These were Hex2 $(1,2)$ and Mdh2 $(3,6)$ for $(38-11$ $\times$ Mol17) x Mo17; Hex2 $(1,2), \operatorname{Mdh} 2(3,6)$ and Idh2 $(4,6)$ for $(38-11 \times$ Oh43) $\times$ Oh43; Hex2 $(4,2)$, Mdh2 $(3.5,6)$ and Pgd1 $(2,3.8)$ for $(B 84 \times$ Oh43) $x$

Table I. Number of resistant (R) and susceptible (S) plants in BC generation, their ratio, $\chi^{2}$ and $P$ values.

$\begin{array}{lcccc}\text { Cross } & \text { Number of R plants } & \text { Number of S plants } & \text { R:S ratio } & \chi^{2} \\ (38-11 \times \text { Mo17 }) \times \text { Mo17 } & 99 & 101 & 1: 1.02 & 0.02 \\ (38-11 \times \text { Oh43) } \times \text { Oh43 } & 78 & 122 & 1: 1.6 & 10.58 \\ (\mathrm{~B} 84 \times \text { Mo17 }) \times \text { Mo17 } & 107 & 91 & 1.17: 1 & 1.29 \\ (\text { B84 } \times \text { Oh43) } \times \text { Oh43 } & 59 & 139 & 1: 2.35 & 20.23\end{array}$




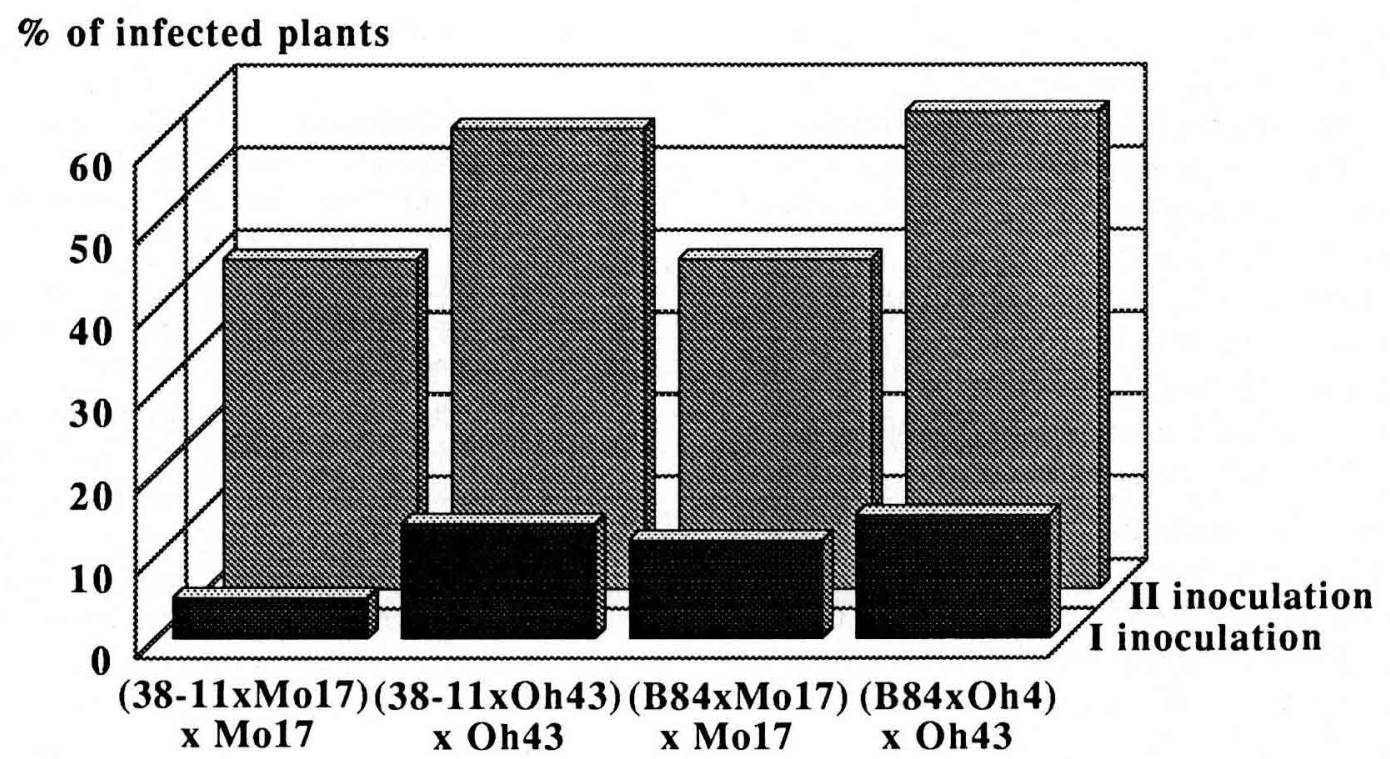

Fig 1. Number of infected plants (expressed in \%) in the BC generation after I and II inoculation.

Oh43. Allele variants of isozyme loci are presented in the brackets. Enp1, with allele form 6, was monomorphic within all analysed lines and as such unusable for further analyses. In isozyme screening of Hex2 and Mdh2 loci of BC progeny of cross (38-11 x Mo17) x Mo17, Hex2 locus was homozygous within all analysed plants and only $3 \%$ of Mdh2 locus were heterozygous. These results could not be used for association determination.

Recombination percentage between Mdm1 and isozyme marker genes is given in table II. This percentage is about $50 \%$ for Hex2, Idh2 and Mdh2 loci, which means that they are not associated with Mdm1. Pgd1 locus is associated with $\mathrm{Mdm} 1$, since the distance between these 2 loci is 14 and 22 in crosses (B84 $\times$ Mo17) $\times$ Mo17 and (B84 x Oh43) $\times$ Oh43, respectively.

\section{DISCUSSION}

If MDMV resistance was determined by one dominant gene, then the $F_{1}$ generation should be uniformly resistant and the $\mathrm{R} v \mathrm{~S} \mathrm{~S}$ ratio in $\mathrm{BC}$ generation should be 1:1. The obtained results were consistent with expected values for crosses to Mo 17 as a susceptible parent. In $F_{1}$ generation of crosses to $\mathrm{Oh} 43$ as a susceptible parent there were plants susceptible to MDMV infection (results are not presented). In the $B C$ generation of the same crosses, the ratio of $R$ vs $S$ plants was much higher than the expected 1:1 ratio. The incubation period was similar for crosses to Mo17 and crosses Oh43. Somewhat higher values for progenies of B84 than for those of 38-11 could probably be explained by a higher resistance of the latter. The data obtained reveal that

Table II. Distance between Mdm1 and isozyme loci (\% of recombination).

Cross

Percentage of recombination

$\begin{array}{cccc}\text { Hex2 } & \text { Mdh2 } & \text { Idh2 } & \text { Pgd1 } \\ 52 & 48 & 46 & - \\ 46 & 50 & - & 14^{\mathrm{a}} \\ 45 & 50 & 50 & 22^{\mathrm{a}}\end{array}$

a Recombination percentage that show gene association. 
the susceptible parent genotype determines the degree of resistance. One possible explanation could be the action of different gene modifications derived from susceptible genotype. Nonrandom (distorted) segregation occurred on Hex2 and Mdh2 loci of BC progeny of cross (38-11 $x$ Mo17 x Mo17). This phenomenon has been noticed previously. It is assumed that non-random segregation is the consequence of multilocus and multichromosomal gamete competition (Wendel et al, 1987; Abler et al, 1991).

Recombination percentages of $\mathrm{Mdm}$ and Hex2, Idh2 and Mdh2 did not show association between these loci. Pgd1 locus is about 14-22 recombination units apart from Mdm1 in (B84 $x$ Mol7 and B84 x Oh43 crosses, respectively). Probably, this percentage is even smaller than calculated, assuming that some plants acted as susceptible even with a resistance allele on Mdm1. In such cases, Mdm1 expression would be depressed or inhibited by the action of modificators from $\mathrm{S}$ parent genotype.

\section{REFERENCES}

Abler BSB, Edwards MD, Stuber CW (1991) Isoenzymatic identification of quantitative loci in crosses of elite maize inbreds. Crop Sci 31, 267274

Findley WR, Dollinger EJ, Louie R, Knoke JK (1973) Locating genes for maize dwarf mosaic resistance by means of chromosomal translocation in com (Zea mays L). Crop Sci 13, 608-611

Ivanović D, Lević J, Satarić I (1992) Inheritance of resistance to maize dwarf mosaic virus in some maize hybrids. Maydica 37, 293-298

Louie R, Findley WR, Knoke JK, McMullen MD (1991) Genetic basis of resistance in maize to five maize dwarf mosaic virus strains. Crop Sci 31, 14-48

Roane CW, Tolin SA, Genter CF (1983) Inheritance of resistance to maize dwarf mosaic virus in maize inbred line Oh7b. Phytopathology 73, 845-850

Rosenkrantz E, Scott GE (1984) Determination of number of genes for resistance to maize dwarf mosaic strain $A$ in five corn inbred lines. Phytopathology 74, 71-76

Scott GE (1989) Linkage between maize dwarf mosaic resistance and endosperm color in maize. Crop Sci $29,1478-1480$

Stuber CW, Wendel JF, Goodman MM, Smith JSC (1988) Technique and scoring procedures for starch gel electrophoresis of enzymes from maize (Zea mays L) NC. State University, Agric Res Service. Tech Bull 286

Wendel JF, Edwards MD, Stuber CV (1987) Evidence for multilocus genetic control of preferential fertilization in maize. Heredity 58, 297-301 